\title{
Postmicturition residual bladder volumes in healthy babies
}

\author{
D S ROBERTS AND B RENDELL*
}

Departments of Paediatrics and ${ }^{*}$ Radiology, St Thomas's Hospital, London

SUMMARY Thirty eight assessments of postmicturition residual volume were undertaken in 34 babies of various gestational and postnatal ages using abdominal ultrasonography. Twenty one $(54 \%)$ babies had no detectable residual bladder volume. In all cases manual expression of the bladder failed to eliminate the residual volume. The formula widely used in the estimation of fetal bladder size and urine output is not applicable in the newborn infant.

Considerable residual postmicturition urine volumes have previously been reported in newborn infants. ${ }^{12}$ This finding effectively invalidates any measured urine output because in the presence of an unknown residual volume such a collection does not reflect the true urine flow rate.

During a recent study on renal function, in which standard clearance methodology was used, we manually expressed the bladder after each void to ensure complete emptying. However, in every case we failed to express any urine. We therefore investigated bladder emptying in a number of healthy babies to establish the incidence of appreciable residual volumes and the value of manual expression.

A mathematical formula, first described for the calculation of fetal bladder volume and derived from bladder measurements obtained on ultrasonography, has been similarly employed in the newborn and we concurrently evaluated its application in this situation. $^{2}$

\section{Subjects and methods}

Abdominal ultrasonography was performed on 34 babies with parental consent; there were 20 boys and 14 girls. Their gestational ages ranged from 24 to 43 weeks and their postnatal ages from 1 to 92 days. Two sets of twins were included. Four babies were studied twice on different days.

All scans were performed using an Advanced Technology Laboratories Mark 100 ultrasonic scanning system. This is a portable, real time sector scanner with a $7.5 \mathrm{MHz}$ rotating wheel transducer. The scans were obtained by a direct scanning technique and the images were recorded on a multiformat matrix.
Scans were taken before and after micturition in longitudinal and transverse planes. From these views measurements of three bladder diameters were obtained using electronic calipers: maximal longitudinal (a), transverse (b), and anteroposterior (c). The bladder volume was calculated using the formula $4 / 3 \times \pi \times a / 2 \times b / 2 \times c / 2 .^{3}$

Where a postmicturition residual volume was detected suprapubic pressure was applied to express the urine.

\section{Results}

Measurements of bladder volume were obtained immediately before voiding in 29 babies and the volume voided measured in 30 . Thirty eight postmicturition scans were obtained.

Bladder volumes were calculated using the formula described: the results are shown in the table.

Twenty one babies $(54 \%)$ emptied their bladder completely. The remainder, seven girls and 10 boys, had a mean calculated residual volume of $1.4 \mathrm{ml}$ (range $0.02-6.6 \mathrm{ml}$ ). Girls had larger calculated residual volumes (mean $2.4 \mathrm{ml})$ than boys $(0.8 \mathrm{ml})$; $\mathrm{p}<0.001$ by Wilcoxon rank sum test. Suprapubic pressure failed to express the residual volumes in all cases.

In 26 of the infants studied measurements for calculation of the volumes before and after micturition were obtained in addition to a measured spontaneous void. When the estimated bladder volume (premicturition volume less the residual volume) was compared with the measured voided volume, there was a positive correlation with an $r$ value of 0.72 . This relatively good correlation, however, concealed a considerable lack of agreement between the two measurements. The mean error of 
Table Details of the 34 babies (38 assessments) and calculated bladder volumes

\begin{tabular}{|c|c|c|c|c|c|c|c|c|}
\hline \multicolumn{2}{|c|}{ Assessment } & \multirow{2}{*}{$\begin{array}{l}\text { Postnatal } \\
\text { age } \\
\text { (days) }\end{array}$} & \multirow{2}{*}{$\begin{array}{l}\text { Gestational } \\
\text { age at } \\
\text { birth } \\
\text { (weeks) }\end{array}$} & \multirow{2}{*}{$\begin{array}{l}\text { Premicturition } \\
\text { calculated } \\
\text { bladder } \\
\text { volume } \\
(\mathrm{ml})(A)\end{array}$} & \multirow{2}{*}{$\begin{array}{l}\text { Actual } \\
\text { voided } \\
\text { volume } \\
(\mathrm{ml})(\mathrm{B})\end{array}$} & \multirow{2}{*}{$\begin{array}{l}\text { Postmicturition } \\
\text { calculated } \\
\text { residual } \\
\text { volume } \\
(\mathrm{ml})(\mathrm{C})\end{array}$} & \multirow{2}{*}{$\begin{array}{l}\text { Calculated } \\
\text { voided } \\
\text { volume } \\
(\mathrm{ml})(A-C)\end{array}$} & \multirow{2}{*}{$\begin{array}{l}\text { Percentage } \\
\text { error in } \\
\text { calculated } \\
\text { void }((A-C)- \\
B / B) \times 100 \%\end{array}$} \\
\hline $\mathrm{No}$ & Sex & & & & & & & \\
\hline 1 & $\mathbf{M}$ & 48 & 29 & - & - & Nil & - & - \\
\hline 2 & $\mathbf{M}$ & 92 & 26 & - & $13 \cdot 6$ & $0 \cdot 10$ & - & - \\
\hline 3 & $\mathbf{F}$ & 23 & 34 & $8 \cdot 6$ & $6 \cdot 6$ & Nil & $8 \cdot 6$ & $30 \cdot 3$ \\
\hline 4 & $\mathbf{M}$ & 34 & 30 & - & - & Nil & - & - \\
\hline 5 & $\mathbf{M}^{*}$ & 9 & 32 & $10 \cdot 2$ & $5 \cdot 6$ & $0 \cdot 10$ & $10 \cdot 1$ & $80 \cdot 4$ \\
\hline 6 & $\mathbf{M}^{* *}$ & 9 & 32 & - & - & Nil & - & - \\
\hline 7 & $\mathbf{F}$ & 7 & 32 & $6 \cdot 2$ & $6 \cdot 3$ & $0 \cdot 30$ & 5.9 & $-6 \cdot 3$ \\
\hline 8 & $\mathbf{M}$ & 5 & 40 & - & - & Nil & - & - \\
\hline 9 & $\mathbf{M}^{*}$ & 14 & 33 & $10 \cdot 1$ & - & Nil & $10 \cdot 1$ & - \\
\hline 10 & $\mathbf{M}^{* *}$ & 14 & 33 & $13 \cdot 8$ & $8 \cdot 2$ & $\mathrm{Nil}$ & $13 \cdot 8$ & $68 \cdot 3$ \\
\hline 11 & $\mathbf{M}$ & 5 & 36 & $5 \cdot 2$ & $3 \cdot 5$ & $0 \cdot 20$ & 5.0 & 42.9 \\
\hline 12 & $\mathrm{~F}$ & 2 & 38 & $10 \cdot 7$ & $8 \cdot 2$ & Nil & $10 \cdot 7$ & $30 \cdot 5$ \\
\hline 13 & $\mathrm{~F}^{* * *}$ & 2 & 37 & - & 3.4 & Nil & - & - \\
\hline 14 & $\mathrm{~F}^{* * *}$ & 9 & 37 & $16 \cdot 2$ & $15 \cdot 3$ & 1.50 & $14 \cdot 7$ & -3.9 \\
\hline 15 & $\mathbf{M}$ & 9 & 36 & $15 \cdot 3$ & $11 \cdot 4$ & $0 \cdot 10$ & $15 \cdot 2$ & $33 \cdot 3$ \\
\hline 16 & M & 78 & 24 & 4.7 & $3 \cdot 8$ & 0.02 & 4.7 & $23 \cdot 2$ \\
\hline 17 & $F$ & 5 & 37 & $10 \cdot 5$ & $5 \cdot 7$ & Nil & $10 \cdot 5$ & $84 \cdot 2$ \\
\hline 18 & $\mathrm{~F}$ & 5 & 41 & $16 \cdot 7$ & $12 \cdot 9$ & Nil & $16 \cdot 7$ & 29.5 \\
\hline 19 & $\mathrm{~F}$ & 1 & 37 & $15 \cdot 8$ & $9 \cdot 0$ & Nil & $15 \cdot 8$ & $75 \cdot 6$ \\
\hline 20 & $M$ & 3 & 37 & $28 \cdot 0$ & $15 \cdot 6$ & $0 \cdot 20$ & $27 \cdot 8$ & $78 \cdot 2$ \\
\hline 21 & M & 3 & 40 & 13.4 & - & Nil & 13.4 & - \\
\hline 22 & $\mathrm{~F}$ & 2 & 43 & - & - & Nil & - & - \\
\hline 23 & $\mathrm{~F}$ & 1 & 40 & $12 \cdot 5$ & $16 \cdot 0$ & 3.00 & $9 \cdot 5$ & $-40 \cdot 6$ \\
\hline 24 & $F$ & 1 & 37 & 6.9 & $8 \cdot 5$ & $0 \cdot 60$ & $6 \cdot 3$ & -25.9 \\
\hline 25 & $\mathbf{M}$ & 3 & 36 & $7 \cdot 0$ & $6 \cdot 0$ & $0 \cdot 10$ & $6 \cdot 9$ & 15.0 \\
\hline 26 & $\mathbf{M}$ & 4 & 36 & - & $22 \cdot 0$ & Nil & - & - \\
\hline 27 & M & 4 & 36 & $12 \cdot 4$ & 11.0 & Nil & $12 \cdot 4$ & 12.7 \\
\hline 28 & $\mathbf{M}$ & 15 & 27 & $3 \cdot 7$ & 3.9 & Nil & 3.7 & $-5 \cdot 1$ \\
\hline 29 & $\mathrm{~F}$ & 2 & 37 & $12 \cdot 7$ & $6 \cdot 0$ & 0.40 & $12 \cdot 3$ & $105 \cdot 0$ \\
\hline 30 & $\mathbf{M}$ & 2 & 40 & 12.9 & $7 \cdot 0$ & 0.70 & $12 \cdot 2$ & $74 \cdot 3$ \\
\hline 31 & $\mathrm{~F}$ & 3 & 38 & 19.9 & $25 \cdot 0$ & Nil & 19.9 & $-20 \cdot 4$ \\
\hline 32 & $\mathrm{~F}$ & 2 & 36 & $15 \cdot 3$ & $12 \cdot 5$ & $4 \cdot 60$ & $10 \cdot 7$ & $-14 \cdot 4$ \\
\hline 33 & M & 3 & 41 & $5 \cdot 6$ & $8 \cdot 5$ & Nil & $5 \cdot 6$ & $-34 \cdot 1$ \\
\hline 34 & $\mathrm{~F}^{* * * *}$ & 74 & 24 & 9.0 & $2 \cdot 0$ & $4 \cdot 10$ & 4.9 & $145 \cdot 0$ \\
\hline 35 & $\mathbf{M}$ & 7 & 37 & $8 \cdot 6$ & - & $6 \cdot 60$ & $2 \cdot 0$ & - \\
\hline 36 & $\mathbf{M}$ & 7 & 40 & - & $20 \cdot 5$ & 0.50 & - & - \\
\hline 37 & $\mathbf{M}$ & 2 & 39 & $17 \cdot 1$ & 19.0 & Nil & $17 \cdot 1$ & $-10 \cdot 0$ \\
\hline 38 & $\mathrm{~F}^{* * * * *}$ & 81 & 24 & 6.9 & $4 \cdot 8$ & Nil & $6 \cdot 9$ & $43 \cdot 8$ \\
\hline
\end{tabular}

Results for babies scanned twice are displayed individually and denoted by paired asterisks.

the calculated compared with actual voided volume was $31 \cdot 2 \%$; this ranged from an underestimation of $40.6 \%$ to an overestimation of $145 \%$ (fig 1 ). Using the paired $t$ test, the two sets of observations were significantly different $(0 \cdot 05>p>0 \cdot 02){ }^{4}$

\section{Discussion}

Our observations indicate that the above formula, in its present form, is not applicable in the assessment of bladder volume in newborn infants. The formula in based upon the assumption that the bladder is ovoid in shape. It was initially validated by scanning the bladder of a term stillborn infant after the intravesical instillation of known volumes of water

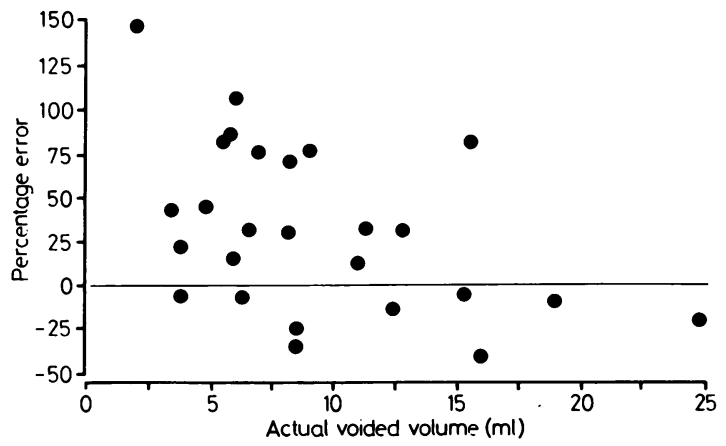

Fig 1 Percentage error of the calculated voided volume when compared with the actual voided volume. 
over a range of $4-39 \mathrm{ml}$, and it has been used widely in the measurement of bladder size and assessment of urine flow rates in the fetus. The reported mean error, on comparison of the actual bladder volume and measurements, was $0.7 \mathrm{ml}$ and it was similar over the range of volumes, indicating that the greater the bladder volume, the greater the accuracy of the method. ${ }^{3}$ In many of our study infants the bladder on ultrasonography appeared complex in shape, particularly in girls where it was crescentic on transverse section, and the residual volumes, where seen, appeared small: these factors may explain the poor accuracy of the calculated values (fig $2 \mathrm{a}, \mathrm{b}, \mathrm{c}$, and d).

Nevertheless our results differ from those of Osborne et al who reported that 15 of 16 babies studied $(94 \%)$ did not empty their bladder completely ${ }^{2} ; 54 \%$ of the infants studied here did.

Babies in the study of Osborne et al were all born at term, with an age range of 2 to 13 days, whereas our infants were of various gestational and postnatal ages. If only the babies of 37 weeks' gestation or greater are considered, however, the percentage who empty their bladder completely remains similar at $58 \%$.

This difference may be related to the type of ultrasound machine used: Osborne and his colleagues used a static scanner and it is possible that during scanning bladder refilling was occurring as measurements were taken, resulting in a higher incidence of residual volume.

Our results also differ from those of O'Donnell
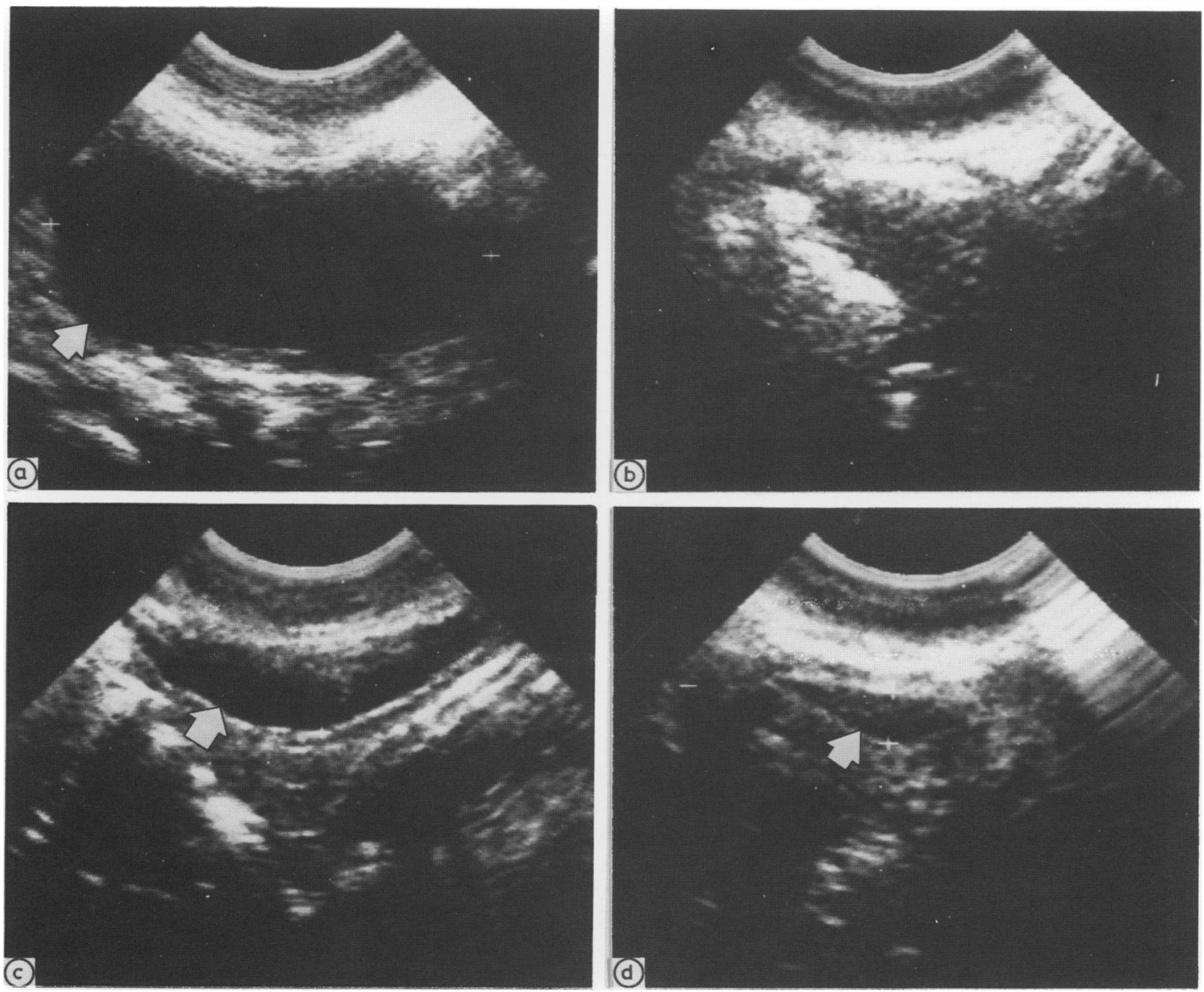

Fig 2 Ultrasound scans of an infant boy before (a) and after (b) micturition showing a complete void. Ultrasound scans of an infant girl before (c) and after (d) micturition showing residual volume and 'crescentic' shape of bladder. (The arrows indicate bladder wall.) 
and O'Connor who reported that large residual volumes were more common in infant boys. ${ }^{1}$

In summary, $54 \%$ of the babies studied emptied their bladder completely. In the remainder a postmicturition volume was detected, however, in most cases this was small, and in all cases it was inexpressible.

We suggest that manual expression after micturition in the newborn is not a useful manoeuvre: it is uncomfortable for the babies and fails to eliminate any residual urine. In addition the formula for estimation of fetal bladder size is not applicable in infants.

\section{References}

1 O'Donnell B, O'Connor TP. Bladder function in infants and children. Br J Urol 1971;43:25-7.

2 Osborne $\mathbf{J}$, du Mont $\mathrm{G}$, Beecroft $\mathbf{M}$, et al. Bladder emptying in neonates. Arch Dis Child 1977;52:896-8.

${ }^{3}$ Campbell S, Wladimiroff JW, Dewhurst CJ. The antenatal measurement of foetal urine production. Journal of Obstetrics and Gynaecology of the British Commonwealth 1973;80:680-6.

${ }^{4}$ Bland JM, Altman DG. Statistical methods for assessing agreement between two methods of clinical measurement. Lancet 1986;i:307-10.

Correspondence to Dr D Roberts, Paediatric Department, 12th Floor, Guy's Tower, London SE1 9RT.

Accepted 24 November 1988 